\title{
Pioneering Video Colonoscopy In Calabar, South-South, Nigeria: A Six-Month Prospective Study.
}

\author{
O E Ngim ${ }^{1}$, UCOkonkwo ${ }^{2}$, MKooffreh - Ada $^{3}$ \\ ${ }^{1}$ Dept of Surgery,University of Calabar Teaching Hospital(UCTH) and JIL Endoscopy, 1 Edyang street,Cross \\ River State Housing Estate,Calabar,Nigeria \\ ${ }^{2 \& 3}$ Dept of Medicine,University of Calabar Teaching Hospital,Calabar,Nigeria
}

\begin{abstract}
Colonoscopy is the gold standard investigative modality in diseases of the large bowel. However, this service is not readily available in Nigeria as in most developing countries in Africa. In addition, lack of appropriate expertize and high cost of the procedure limits its use in our environment. This is the first report on colonoscopy from this part of Nigeria.The aim of this study was to evaluate the indications, demographic data and endoscopic findings of patients who presented for colonoscopy in JIL Endoscopy, a private endoscopy centre in Calabar,Nigeria. A total of 20 patients had colonoscopy in this centre during the 6-month study period. There were fifteen males and five females with a male to female ratio of 3:1. The age range was 17-78 years with a mean age of 46.3 years. The commonest indication was bleeding per rectum in 16 (80\%) patients. The commonest endoscopic finding was hemmorhoids in $9(45 \%)$ patients followed by colorectal cancer and inflammatory bowel disease with 3 (15\%) cases each.
\end{abstract}

Keywords: Pioneering, videocolonoscopy, Calabar, Nigeria .

\section{Introduction}

Colonoscopy is presently not readily available in most centres in Nigeria as well as most developing countries. It is the gold standard for the diagnosis of large bowel diseases because it is possible to visualize the entire large bowel up to the caecum with good bowel preparation, appropriate expertize and facility ${ }^{1-7}$. Colonoscopy is the only major advancement in the diagnosis of colonic disease since the performance of the first barium enema in $1905^{4}$. There are several indications for colonoscopy ranging from lower GI bleeding, change in bowel habit, suspected colorectal cancer, anaemia of unknown origin etc. ${ }^{1-7}$. The aim of this study was to determine the indications, demographic characteristics and endoscopic findings of patients undergoing colonoscopy in the only private endoscopy facility offering this service in Calabar ,South-South, Nigeria.

With appropriate expertize, good bowel preparation and patient comfort, colonoscopy is a safe procedure with very high yield ${ }^{1-4}$. Although colonoscopy is the gold standard for making the diagnosis of colorectal cancer, it is however, highly underutilized in Nigeria and sub-Saharan Africa ${ }^{3,5,6}$ owing largely to it's poor availability, high cost and lack of appropriate expertize. Colorectal cancer continues to be a burden worldwide, with increasing incidence in different parts of the world ${ }^{3,5,6,8,9}$. Onyekwere et al ${ }^{12}$ cited a recent study in Ibadan ,South West, Nigeria, with an $81 \%$ increase in the incidence of colorectal carcinoma over a period of two decades ${ }^{12}$.Screening colonoscopy especially where fecal occult blood is positive is an important diagnostic tool that can reverse the current trend of late presentation of patients with colorectal carcinoma ${ }^{1-7,10}$.

\section{Materials and Methods}

This was a six-month prospective study carried out in JIL Endoscopy, a private endoscopy facility in Calabar using an Olympus CF-140L Video Colonoscope. This centre receives referrals from different parts of Cross River State and Akwa Ibom state both in the South-South region of Nigeria. Bowel preparation before the procedure, was done with oral dulcolax tablets and castor oil/oral mannitol in addition to dietary modification. Eighty five percent of these patients had a two day bowel preparation. This was done with dulcolax tablets two days prior to the procedure and oral $20 \%$ or $10 \%$ mannitol a night before the procedure. The patients had normal meals until a day before the procedure, when they had low residue diet. The remaining group had a four day preparation with dulcolax tablets, dietary modification, soap and water enema and castor oil. The procedure was done under conscious sedation using intravenous midazolam and pentazocine at appropriate titrated doses. Each patient had supplemental oxygen administered throughout the procedure with nasal prongs while a pulse oxymeter was used to monitor the patient's saturation and pulse throughout the procedure. After the procedure, patients were escorted back home by a responsible adult and they were told not to drive or engage in any activity requiring co-ordination until the effect of the sedative was over. 


\section{Results}

A total of 20 colonoscopies were done within the study period, giving an average of 3 cases per month. There were $15(75 \%)$ males and $5(25 \%)$ females with a male: female ratio of $3: 1$. The age range was 17-78 years with a mean age of 46.3 years. The commonest indication for colonoscopy was bleeding per rectum in $16(80 \%)$ patients, followed by change is bowel habit in $3(15 \%)$ cases. Anaemia of unknown origin was an indication in one $(5 \%)$ patient. The commonest finding at colonoscopy was hemorrhoids in $16(45 \%)$ patients, followed by colorectal cancer and inflammatory bowel disease in three (15\%) patients each and diverticular disease of the colon in two $(10 \%)$ patients. Three patients $(15 \%)$ had normal findings at colonoscopy (The indication for two of these patients were change in bowel habit while the remaining patient, a middle-aged man, had anaemia of unknown origin). Figl\&2 showed colonic cancer and diverticular disease of the colon respectively as seen in two patients in this series. In this series, the use of mannitol gave a better bowel preparation compared to the use of castor oil and soap and water enema. Also, it was noted that the average age of patients who had diverticular disease, colorectal cancer and hemorrhoids were 69 years,54.7 years and 41.8 years respectively. No complication was recorded during these procedures. Caecal intubation was achieved in $19(95 \%)$ patients.
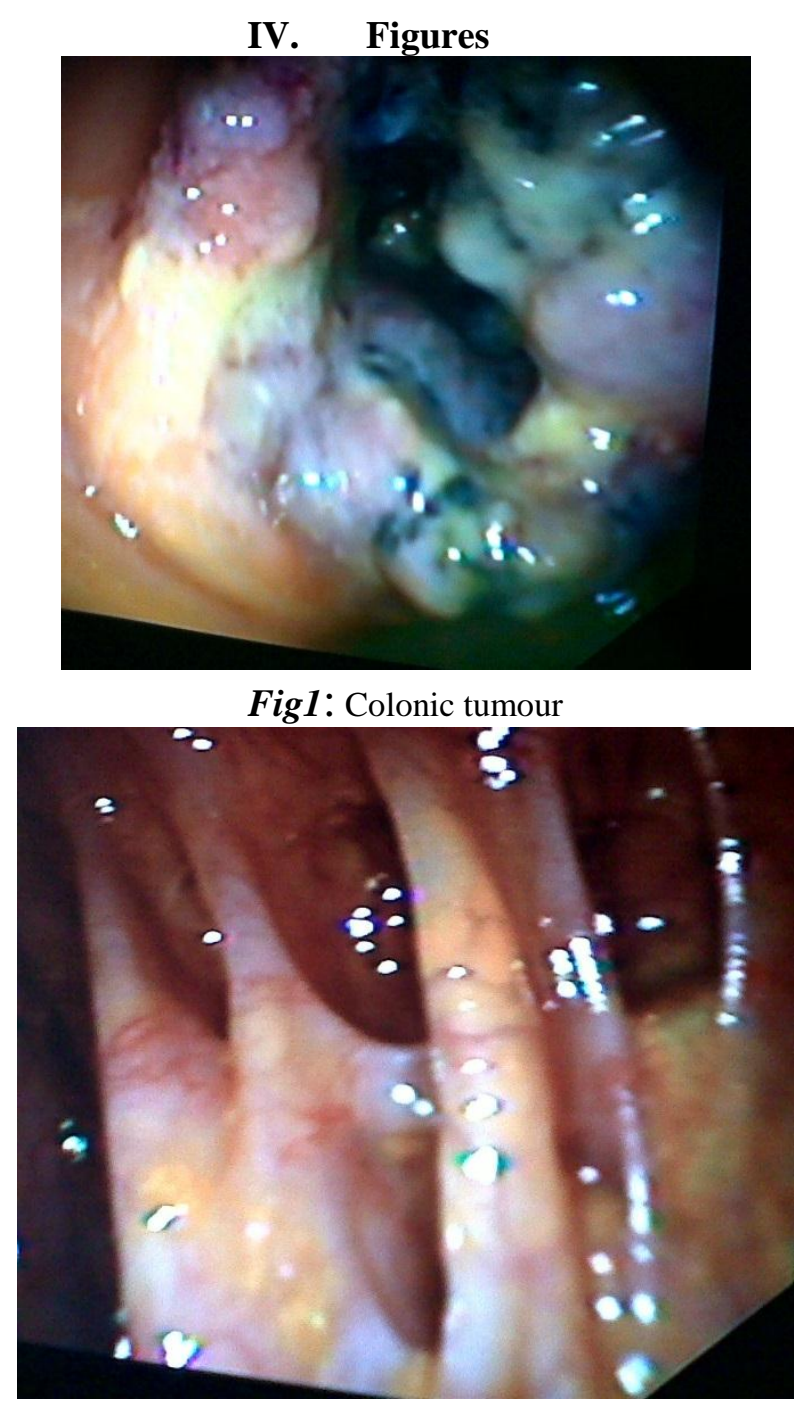

Fig 2: Diverticular disease of the colon

\section{Discussion}

Colonoscopy remains the gold standard for the diagnosis of diseases of the large bowel. The diagnostic yield of colonoscopy from our data was $85 \%$. The number of patients seen in our present study is similar to that reported by some workers in Nigeria ${ }^{1,3}$ though some other studies in Nigeria reported higher figures of colonoscopies done $e^{2,4-5}$. The studies with higher figures were done in tertiary health facilities and over longer duration of time. In these tertiary centres, apart from the fact that patient population is more, awareness of the 
availability and usefulness of colonoscopy is higher and the cost lower since services in these centres are often subsidized by the Government. All this makes it possible for more patients to have colonoscopy in these centres compared to a private facility. It is intriguing to note that whereas Arigbabu et $a l^{4}$ in Ile-Ife recorded 562 colonoscopies over a four year period (1978-1982), giving an average of 140 cases per year (i.e 12 cases per month), Alatise et al recorded 320 cases over a five year period (2007-2011) in the same tertiary health institution twenty nine years later, giving an average of 64 cases per year or 5 cases per month. This clearly shows a marked decline in the number of colonoscopies done in this centre and the reason for this drop is puzzling since the incidence of conditions requiring colonoscopy such as colorectal carcinoma are on the increase in Nigeria ${ }^{3,7,12}$. The data by Alatise et al when compared with our present data will only be 10 cases above what we had in 6 months which suggest that the number in our study may not be considered small.

Onyekwere $e t a l^{3}$ did a multi-centre study of patients who had colonoscopy in Lagos, Nigeria. They had a total of 607 patients from eight centres over 18 months, giving an average of 4 cases per centre per month. The figure of 3 cases per month in our present study compares favorably with that of Onyekwere et al. Findings from our present study is particularly interesting since colonoscopy is just beginning in this part of Nigeria and awareness is still very low. Olokoba ${ }^{\text {et al }}$ in Ilorin, South West Nigeria even had an average 3 colonoscopies per month in a tertiary health facility in Nigeria. All these point to the low utilization of colonoscopy in Nigeria as documented in the literature. ${ }^{1-3,5}$.

The diagnostic yield of colonoscopy in our study was $85 \%$. Olokoba $e$ t al $l^{1}$, Alatise $e t a l^{2}$, Onyekwere $e t$ $a l^{3}$ and Ismaila $e t a l^{5}$ reported $79.6 \%, 90.99 \%, 76.6 \%$ and $79 \%$ diagnostic yield respectively in their series. All these, validate the usefulness of colonoscopy in large bowel pathology. These authors ${ }^{1,2,3,5}$ all had more males than females undergoing this procedure which is similar to our findings. The mean age in our study was 46.3 years with a range of 17-78years. This compares with the mean age recorded by Ismaila et $^{2} l^{5}$ in Jos, Nigeria with a mean age of 43.5 years but with a range of 8-80 years. It is evident that paediatric patients had colonoscopies done in studies by Olokoba et al (age range, 6-84 years), Alatise et al (age range 2-87 years) and Ismaila et al (age range $8-80$ years) ${ }^{1,2,5}$. It is important to note that a paediatric colonoscope is required to scope children.

The commonest indication for colonoscopy in our series was rectal bleeding which agrees with documentation in the literature. ${ }^{1,2,3,4,6,7}$. The commonest colonoscopic finding in our series was hemorrhoids $(45 \%)$ which agrees with findings by Alatise et $\mathrm{al}^{2}$, Onyekwere et $\mathrm{al}^{3}$. An important aspect of our study which gives a lot of hope for the detection of colorectal cancer is the finding of 3(15\%) cases of colonic tumour amongst these few number of colonoscopies done. This adds credence to the need for colonoscopy in patients with lower GI symptoms, even as a screening procedure as early detection of colorectal malignancy will improve prognosis $1,6,7,8,9$.

The high caecal intubation rate in our series (95\%) may be a function of the small sample size when compared with that of Onyekwere et $\mathrm{al}^{3}$ who recorded $82 \%$. Though some studies found polyps in the colon, $1,2,3,5$,these were not recorded in our series thus far. Also, the ages of patients with diverticular disease of the colon seen in our study agrees with the age at which they are common in the literature ${ }^{5,6,7}$. There was no complication recorded in our series. Overall, colonoscopy is a safe procedure when done by trained personnel as alluded to by other workers in this field ${ }^{1-5}$.

\section{Conclusion:}

Colonoscopy remains the gold standard for establishing the diagnosis of diseases of the large bowel. This preliminary report has demonstrated a high yield from colonoscopy in detecting large bowel diseases and in particular colorectal cancer. More awareness needs to be created and it may be possible to pick up colorectal malignancies early and improve the prognosis.

\section{References:}

[1]. A B Olokoba ,O A Obateru, M O Bojuwoye,S A Olatoke, O A Bolarinwa, L B Olokoba. Indications and findings of colonoscopy in Ilorin,Nigeria.Niger Med J 2013,54(2),111-114.

[2]. OIAlatise, AOArigbabu, EAAgbakwuru, OOLawal, DANdububa, OSOjo. Spectrum of colonoscopy findings in Ile-Ife, Nigeria. NPMJ 2012,19(4),219-224.

[3]. CAOnyekwere, JNOdiagah, OOOgunleye, CChibututu, OALesi. Colonoscopy practice in Lagos Nigeria: A report of an Audit. Diagnostic and Therapeutic Endoscopy 2013,2013 Article ID 798651, 6 pageshttp://dx.doi.org/10.1155/2013/798651

[4]. AOArigbabu, WOOdesanmi. Colonoscopy. First Experience in Nigeria. Dis Colon Rectum 1985,28(10),728-31

[5]. BO Ismaila, MA Misauno . Colonoscopy in a Tertiary Hospital in Nigeria. Journal of Medicine in the Tropics,2011,13(2)

[6]. J Lindsay. Gastrointestinal endoscopy. In NSWilliams,CJKBulstrode,P Ronan O'Connell (eds.) Bailey and Love's Short Practice of Surgery,25( London: Arnold 2008)163-166.

[7]. EABadoe,EA Nwako,EQArchampong, JTda-Rocha-Afodu, SBNaaeder ,NEN Obianyo. Small and Large intestines(Including Rectum and Anus). In : EABadoe, EQArchampong,JTda-Rocha-Afodu (eds). Principles and Practice of Surgery -Including Pathology in the Tropics, 4( Accra: Assemblies of God Literature Centre Ltd. 2009) 719-731. 
[8]. K H Makambi, T Agurs-Collins, M Bright-Gbebry, L Rosenberg, J R Palmer, L L Adams-Campbell.Dietary Patterns and the Risk of Colorectal Adenomas: the Black Women's Health Study. Cancer Epidemiol Biomarkers Prev, 20(5), 818-25. (C2011 $A A C R$.

[9]. M M Center, A Jemal ,E Ward. International Trends in Colorectal Cancer Incidence Rates.Cancer Epidemiol Biomarkers Prev 2009,18(6),1688-94

[10]. Madiba TE. Colorectal Carcinoma.In: A Adeloye,O O Adekunle,O A Awojobi, (eds). Davey’s Companion To Surgery In Africa,3( Ed.Acecool Medical Publishers,Eruwa,Nigeria,2009)361

[11]. N Mahmoud,J Rombeau,H M Ross,R D Fry. Colon and Rectum. In M Courtney,RBeauchamp,BEvers,KMattox (eds). Sabiston Textbook of Surgery, 17 (Ed.Elsevier Saunders 2004)1415-1420

[12]. C A Onyekwere,A OOgbera, F B Abdulkareem, J Ashindoitiang. Colorectal Carcinoma Screening in Lagos,Nigeria,Are we Doing it Right? Gastroenterology Research 2009(2) 38-42. 